\title{
CHARACTERISTICS OF WAITING LINE MODELS - THE INDICATORS OF THE CUSTOMER FLOW MANAGEMENT SYSTEMS EFFICIENCY
}

\author{
Sidonia Otilia Cernea ${ }^{1}$ \\ Mihaela Jaradat ${ }^{2}$ \\ Mohammad Jaradat ${ }^{3}$
}

\begin{abstract}
This paper is dedicated to the presentation of the single-channel waiting line systems with Poisson arrivals and exponential service times.They represent stages of customer flow management processes. Waiting systems are stochastic mathematical models and they represent the describing base of the waiting phenomena, service processes, prioritization, etc. Mathematical models of queuing theory present interest in modeling, designing and analysing of nowadays information networks. Increasing trend of their development and emergence of new network technologies, impose new requirements regarding the development of new mathematicals waiting models. In this paper we merely present the single-channel waiting line model, with example on a fast-food restaurant.
\end{abstract}

Key words: customer flow, queuing theory, waiting system, waiting line, efficiency

JEL codes: A12, C41, C46, L84

\section{Introduction}

There are many cases when we face the waiting situation. We find ourselves in such situations everyday at checkouts, in supermarkets, banks, restaurants, etc. In order to reduce the time spent in waiting systems, one solution would be to supplement the checkout clerks, but this is not always the most economical strategy to improve services.

One of the factors influencing consumers' perception on service quality is the efficiency of waiting systems. The waiting time is inevitable in the case of random requests. Thus, providing the capacity for a sufficient service is needed, but it is involving high costs. This is the premise from which the queuing theory starts in designing service systems (Alecu, F., 2004).

Customer flow management refers to customer flow handling as well as to their experiences from the first contact with the company until the delivery of goods/services. Customer flow management plays a key role in increasing the productivity, sales and also in reducing costs, since each customer will be directed to the right place, at the right time and will be served by the adequately operator. Thus, the steps of the customer flow are as follows ${ }^{4}$ :

- $\quad$ pre-reception - involves using programming in advance, thus resulting a shorter waiting time. It can be made by phone or using the Internet;

- $\quad$ reception - customer flow management is opting to place customers in different waiting lines, depending on their needs;

\footnotetext{
1 "Bogdan Vodă” University, Gr. Alexandrescu street, no. 26A, Cluj-Napoca, România, sidonia.cernea@ubv.ro

2 "Bogdan Vodă” University, Gr. Alexandrescu street, no. 26A, Cluj-Napoca, România, mihaelajaradat@yahoo.com

3 "Bogdan Vodă” University, Gr. Alexandrescu street, no. 26A, Cluj-Napoca, România, jaradat_hadi@yahoo.com

$4 * * * h t t p: / / w w w . e u t r o n . r o / c a t e g o r i e / s i s t e m e-s i-p r o d u s e / s i s t e m e-d e-m a n a g e m e n t-a l-f l u x u r i l o r-d e-c l i e n t i / 19 /$
} 
- $\quad$ waiting - waiting time optimization can be achieved by improving the staff planning and increasing the processes flexibility;

- $\quad$ service - once the customers are waiting in a line, the staff can start the required services;

- $\quad$ post-service - after serving, waiting and proceeding times are recorded by the staff;

- administration - the records can be used to the current processes assessment, by generating reports, in order to determine the operational efficiency.

\section{Literature review}

In the literature, there were developed some models in order to support and assist managers in making the best decisions on waiting lines (Pang, P., 2004), (Sweeney, D. et. al. 2010). In the management terminology, a waiting line is also called the tail and their characteristic concepts form the queuing theory (Shim, J., K., Siegel, J., G., 1999), (Williams, A., S., 2003). This theory is underlying the analysis of some communication, logistic, manufacturing and services systems (Bejan, A., 2007). The main advantage of queuing theory resides in determining very important information about waiting times, arrivals and service stations characteristics and about the systems discipline (Alecu, F., 2004).

Waiting line models consists of mathematical formulas and relations used to determine the operating characteristics of these lines. Among these features we mention (Williams, A., S., 2003):

- $\quad$ the probability that there is no item in the system;

- the average of the items in the waiting line;

- the average of the existent items in the system (the items in the waiting line and the items being served);

- $\quad$ the average time an item spends in the waiting line; the service time);

- the average time an item spends in the system (consists of the waiting time besides

- the probability that an item has to wait for the service.

\section{Research methodology}

In order to highlight the characteristics of a waiting system, we consider the example of a fast-food restaurant. Although every fast-food restaurant wants to provide a service as prompt as possible, there are many cases when the personal can't handle the customers. Thus the waiting situations arise.

\section{Single-channel waiting line}

The way the customers are served in a fast-food restaurant is an example of a single-channel waiting line. That is, the customer order is taken and as the transaction is completed, the order of the next customer in the waiting line is taken. Thus, each customer of the restaurant goes through a single-channel where he places the order, pays and picks-up the products. If there are more customers than can be served, a waiting line arises. The diagram below shows a single-channel waiting line for the fast-food restaurant: 


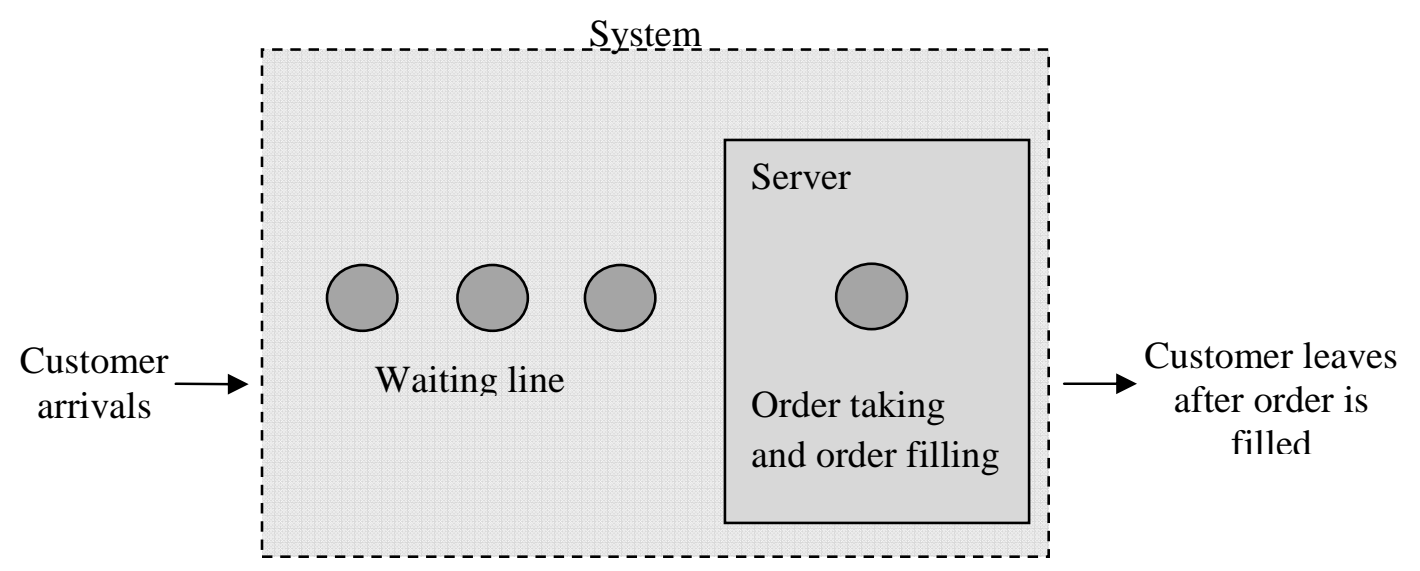

Fig. no. 1 - The fast-food single-channel waiting line

\section{Distribution of arrivals}

Source: Williams, 2003

A feature of the arrival process is the probability distribution of arrivals in a given time period. In many situations, arrivals occur randomly and independently of other arrivals, such that the estimation of an arrival occurrence is difficult to determine. Thus, the Poisson distribution is the best solution to describe the arrivals pattern.

Starting from the definition of a Poisson distribution of random variables [4], the probability distribution function of $x$ arrivals in a specific time period, is:

$$
P(x)=\frac{\lambda^{x} e^{-\lambda}}{x !} \text { for } x=0,1,2, \ldots
$$

where: $x$ - the number of arrivals in a time period;

$\lambda$ - the mean number of arrivals per time period;

$e=2.71828$.

Supposing that in our fast-food, the mean number of arrivals is 45 customers per hour, the mean number of customers arrived in one minute is $\lambda=45 / 60=0.75$. The probability that $x$ customers arrive in one minute period will be:

$$
P(x)=\frac{\lambda^{x} e^{-\lambda}}{x !}=\frac{0.75^{x} e^{-0.75}}{x !}
$$

The probabilities of $0,1,2$ arrivals in one minute period will be:

$$
\begin{gathered}
P(0)=\frac{(0.75)^{0} e^{-0.75}}{0 !}=e^{-0.75}=0.4274 \\
P(1)=\frac{(0.75)^{1} e^{-0.75}}{1 !}=0.75 e^{-0.75}=0.3543 \\
P(2)=\frac{(0.75)^{2} e^{-0.75}}{2 !}=0.28125 e^{-0.75}=0.1329
\end{gathered}
$$




\section{Service time distribution}

Service time starts when a customer places an order and finishes when the customer receives the order. Service time is not constant, but it depends on how large the order is.

The quantitative analysis highlighted the fact that the exponential distribution of the service time provides the best information regarding the operations of waiting line. If the exponential probabilistic distribution is used then the probability that the service time is less than or equal to a ime $t$ will be (Jaradat M., Mureşan, A., 2004), (Williams, A., S., 2003):

$$
P\left(t_{s} \leq t\right)=1-e^{-\mu t}
$$

where: $t_{s}$ - the time for service;

$t$ - the length of the specified time period;

$\mu$ - the mean number of items that can be served in a period;

$e=2.71828$.

For example, suppose that in our fast-food, an operator serves an average of 60 customers per hour. Then, in one minute, the operator will serve $\mu=60 / 60=1$ customer.

If $\mu=1$, we can determine what is the probability of an order to be processed in $1 / 2$ minute or less, in 1 minute or less, or in 2 minutes or less. Thus, from (6) results:

$$
\begin{gathered}
P\left(t_{s} \leq 0.5\right)=1-e^{-0.5}=0.3935 \\
P\left(t_{s} \leq 1\right)=1-e^{-1}=0.6321 \\
P\left(t_{s} \leq 2\right)=1-e^{-2}=0.8647
\end{gathered}
$$

\section{Waiting line discipline}

When talking about waiting systems and lines, it is necessary to specify the way the elements are arranged for serving, in other words it has to specify the waiting line discipline. In case of fast-food restaurant, as in other many cases, the queue discipline is the FIFO type (First In First Out). In other words, the customers are served in order of their arrival in the waiting line. There are situations when the waiting line discipline is type of LIFO (Last In First Out). Such an example is given by persons who are going to use an elevator. Thus, the last person entered the elevator will be the first person to leave it. There are real systems in which the requests need to be served before other based on some priorities (Benderschi O., 2009).

\section{Single-channel waiting line model, with Poisson arrivals and exponential service time}

In order to be able to highlight the way the existing formulas can provide information related to the waiting line characteristics, we turn to our fast-food restaurant example.

Next, we present the characteristics of the waiting line operations, taking into account the following: $\lambda$ - the average number of arrivals in a given period of time and $\mu$ - the average number of services in a given period of time (Williams, A., S., 2003):

- the probability that there is no item in the system:

$$
P(0)=1-\frac{\lambda}{\mu}
$$


- the average number of items existing in the waiting line:

$$
L_{q}=\frac{\lambda^{2}}{\mu(\mu-\lambda)}
$$

- the average number of items existing in the system:

$$
L=L_{q}+\frac{\lambda}{\mu}
$$

- the average time spent by an item in the waiting line:

$$
W_{q}=\frac{L_{q}}{\lambda}
$$

- the average time spent by an item in the system:

$$
W=W_{q}+\frac{1}{\mu}
$$

- the probability that an item is waiting to be served:

$$
P_{w}=\frac{\lambda}{\mu}
$$

- the probability that there are $n$ items in the system:

$$
P_{n}=\left(\frac{\lambda}{\mu}\right)^{n} P_{0}
$$

It is worthy to note that the formulas from (10) to (16) can be applied only if $\mu$ is greater than $\lambda$. In other words, they can be applied only if $\lambda / \mu<1$. Failing to meet this condition leads to a growing of the waiting line, because the service capacity is insufficient.

Next, we are going to determine the operations characteristics in case of fast-food restaurant. Based on previously determined values for $\lambda=0.75$ and $\mu=1$ and using formulas (10) - (16), we get: 


$$
\begin{aligned}
& P(0)=1-\frac{0.75}{1}=0.25 \\
& L_{q}=\frac{(0.75)^{2}}{1(1-0.75)}=2.25 \text { customers } \\
& L=2.25+\frac{0.75}{1}=3 \text { customers } \\
& W_{q}=\frac{2.25}{0.75}=3 \text { min utes } \\
& W=3+\frac{1}{1}=4 \text { min utes } \\
& P_{w}=\frac{0.75}{1}=0.75
\end{aligned}
$$

\section{Waiting lines models utility}

In case of the considered fast-food, the results highlight some important issues about the waiting line operation mode. Thus, the customers have to wait an average of 3 minutes to place an order; the average number of customers who have to wait is 2.5 and $75 \%$ of arriving customers have to wait for the order. These values show that it is necessary to improve the operations occurring within the waiting line. If the managers continue to use the single-channel waiting line, the number of waiting customers will be increasingly higher.

\section{Conclusions}

The waiting line models play a key role in highlighting the operations effectiveness and hence the need of improving their characteristics. The analysts are those who decide if there will be any changes regarding the waiting line configuration. In general, in order to improve the operations within the waiting line, they appeal to improve the service rate. This is possible by adopting one or both solutions listed below:

- the increase of the average service rate $\mu$ - this is possible by either redesigning the waiting line or using the new technologies;

- the addition of new service channels - so that more customers can be served simultaneously.

\section{References}

1. Alecu, F., 2004. "Sisteme de aşteptare pentru calculul paralel şi distribuit", Romanian Journal of Information Technology and Automatic Control, Vol. 14, No. 2.

2. Bejan, A., 2007. Modelarea timpului de orientare în sisteme de aşteptare cu priorităţi, Paper of the $\mathrm{PhD}$ thesis in physical-mathematical sciences, Chişinău, (available online at http://www.cnaa.md/files/theses/2007/6944/andrei_bejan_abstract.pdf).

3. Benderschi O., 2009. Analiza sistemelor de aşteptare cu priorităţi şi trafic critic, Paper of the $\mathrm{PhD}$ thesis in physical-mathematical sciences, Chişinău, (available online at http://www.cnaa.md/files/theses/2009/13911/olga_benderschi_abstract.pdf).

4. Jaradat M., Mureşan, A., 2004. Matematici pentru economişti. Teorie şi aplicaţii, Risoprint Publishing, Cluj-Napoca.

5. Pang, P., 2004. Essentials of Manufacturing Engineering Management, iUniverse Inc., USA.

6. Shim, J., K., Siegel, J., G., 1999. Operations Management, Barron's Educational Series, USA.

7. Sweeney, D., J., Anderson, D., R., Williams, T. A., Camm, J., D., Kipp, Martin, R. 2010. Quantitative Methods for Business, Cengage Learning, USA. 
8. Williams, A., S., 2003. An Introduction to Management Science - Quantitative Approaches to Decision Making. Tenth Edition, South-Western, USA.

9. ***http://www.eutron.ro/categorie/sisteme-si-produse/sisteme-de-management-al-fluxurilor-declienti/19/ 